Cahiers $d u$ MONDE RUSSE

\section{Cahiers du monde russe}

Russie - Empire russe - Union soviétique et États indépendants

$43 / 4 \mid 2002$

Intellectuels et intelligentsia

\title{
Frédéric Bertrand, L'anthropologie soviétique des années 20-30
}

Juliette Cadiot

\section{OpenEdition}

Journals

Édition électronique

URL : https://journals.openedition.org/monderusse/4030

DOI : 10.4000/monderusse.4030

ISSN : $1777-5388$

Éditeur

Éditions de l'EHESS

\section{Édition imprimée}

Date de publication : 30 décembre 2002

Pagination : 725-727

ISBN : 2-7132-1796-2

ISSN : $1252-6576$

Référence électronique

Juliette Cadiot, «Frédéric Bertrand, L'anthropologie soviétique des années 20-30», Cahiers du monde russe [En ligne], 43/4 | 2002, mis en ligne le 17 juin 2009, consulté le 03 septembre 2022. URL : http:// journals.openedition.org/monderusse/4030; DOI : https://doi.org/10.4000/monderusse.4030

Ce document a été généré automatiquement le 3 septembre 2022

Tous droits réservés 


\title{
Frédéric Bertrand, L'anthropologie soviétique des années 20-30
}

\author{
Juliette Cadiot
}

\section{RÉFÉRENCE}

Frédéric BERTRAND, L'anthropologie soviétique des années 20-30. Configuration

d'une rupture. Pressac, Presses Universitaires de Bordeaux, 2002, 344 p.

1 Le livre de Frédéric Bertrand se présente comme une étude anthropologique, basée sur la consultation d'archives et sur des entretiens, d'une période considérée comme charnière pour l'ethnographie soviétique, époque de purges et de «marxisation» de la fin des années 1920 et des années 1930. Le projet de l'auteur est de déconstruire la notion de rupture, associée à la période de stalinisation de la science, de la démystifier par une description minutieuse des événements, des discours et stratégies des chercheurs. Frédéric Bertrand s'applique à décrire les moyens par lesquels les ethnographes ont utilisé plusieurs discours de légitimation de leur discipline, en particulier celui de la rupture avec la science bourgeoise, dans un contexte mouvant et dangereux. Pour ce faire, l'auteur fait un large usage des concepts de la sociologie des sciences, en particulier ceux promus par Michel Callon et Bruno Latour, visant à ouvrir « la boîte noire » de l'ethnographie soviétique et à en dédramatiser l'histoire. Il en conclut que, malgré les tragédies personnelles, les ethnographes ont réussi à préserver leur discipline, ainsi que ses concepts et méthodologies fondamentales, et qu'il est dès lors impossible de parler d'« ethnographie soviétique » ou d'« ethnographie marxiste ». Le livre rompt avec un discours interne à la discipline qui explique et écrit son histoire en fonction du traumatisme, tant humain que scientifique, des années 1930.

2 Si la thèse de la continuité nous semble intéressante, c'est parce qu'elle permet, par exemple, l'analyse de la pérennité de notions comme l'ethnos ou de méthodologies privilégiant les études de terrain. Le parti pris de Frédéric Bertrand ne se situe pourtant pas dans une perspective d'explication des convictions et des traditions scientifiques 
propres à l'ethnographie russe, même si son livre (et en particulier la troisième partie) fournit de nombreuses informations et analyses à ce sujet.

3 L'auteur réussit par la micro-analyse à "normaliser " l'étude de la science soviétique, sujette comme partout ailleurs à la vie de laboratoire avec ses compromis, ses actes d'allégeance et ses recherches d'autonomie. Mais le livre tend finalement à démontrer l'évidence du fait que, pointés du doigt par le pouvoir, les ethnographes ont tenté à tout prix de sauver leur discipline et leurs vies, qu'ils se sont placés dans un espace brouillé entre compromission et recherche de préservation de leur indépendance. La question de savoir si la politique répressive du régime a pu paradoxalement avoir comme effet une crispation des chercheurs sur leurs outils d'analyse traditionnels n'est pas vraiment posée.

Surtout, un des problèmes de la méthodologie ici utilisée est qu'elle offre finalement une histoire des sciences strictement internaliste. Aussi, si Frédéric Bertrand affirme à plusieurs reprises qu'il est impossible de strictement délimiter la sphère scientifique de celles $\mathrm{du}$ social et $\mathrm{du}$ politique, ces deux dernières apparaissent trop peu. Les ethnographes sont rarement placés dans l'espace social et surtout politique, la politique des nationalités et le travail d'expertise auquel ils sont conviés sont peu décrits; enfin leurs convictions et leur travail scientifiques sont presque exclusivement traités en termes de stratégie. Alors que les thèmes abordés et l'analyse du travail des ethnographes sont fondamentaux pour une juste compréhension de ce que fut l'Union soviétique et que l'auteur offre sur ce point des informations très utiles, il est difficile pour le lecteur d'en mesurer l'enjeu. Aussi ce dernier aurait-il été intéressé, au-delà d'une description visant avec raison à normaliser l'histoire de la discipline et à décrire la science telle qu'elle se fait, à en saisir les discussions. Et il n'est pas sûr que dans cette perspective, les changements de paradigmes exigés par le pouvoir soviétique aient été si peu porteurs de sens. Normaliser peut tout aussi bien signifier expliquer les débats, en les reliant en particulier à des problématiques sur la constitution des sciences sociales et sur leur rapport à la construction politique. Enfin le choix, qui n'était pas celui de la thèse, de s'en tenir presque exclusivement à des analyses de discours et de n'aborder que très peu les processus concrets d'institutionnalisation, ne permet pas de prendre la mesure réelle des problèmes de légitimation et de constitution disciplinaire auxquels la génération d'ethnographes décrite ici a dû s'affronter. 